\title{
DEMANDA ENERGÉTICA DE UMA SEMEADORA-ADUBADORA PARA SOJA SOB DIFERENTES VELOCIDADES DE DESLOCAMENTO E COBERTURAS DO SOLO ${ }^{1}$
}

\author{
VIRINDIANA C. BORTOLOTTO², RAIMUNDO PINHEIRO NETO ${ }^{3}$, \\ MARCIANO C. BORTOLOTTO ${ }^{4}$
}

\begin{abstract}
RESUMO: O objetivo deste trabalho foi avaliar a demanda energética requerida por uma semeadoraadubadora disponível comercialmente para plantio direto, submetida a quatro velocidades de deslocamento e três condições de cobertura do solo na implantação da cultura da soja. O experimento foi conduzido no Sítio Cazarotto, localizado no Distrito de Iguatemi, município de Maringá - PR, em Latossolo Vermelho distrófico. Utilizou-se de delineamento de blocos ao acaso, em arranjo de parcelas subdivididas, em que os tratamentos principais foram três condições de cobertura do solo (vegetação espontânea, aveia dessecada e aveia dessecada + rolada) e as secundárias, quatro velocidades de deslocamento $\left(4,7 ; 5,4 ; 6,5\right.$ e 7,2 $\left.\mathrm{km} \mathrm{h}^{-1}\right)$. As variáveis estudadas foram: força na barra de tração, potência requerida, patinagem do rodado traseiro do trator e consumo de combustível. A força de tração foi influenciada pela velocidade de deslocamento e pelas condições de cobertura. A patinagem dos rodados do trator não foi influenciada pelos tratamentos. O consumo horário de combustível foi maior na condição de cobertura vegetação espontânea.
\end{abstract}

PALAVRAS-CHAVE: força de tração, potência requerida, consumo de combustível.

\section{SEEDER ENERGETIC DEMAND IN SOYBEAN CULTURE IMPLANTATION UNDER DIFFERENT DISPLACEMENT SPEEDS AND SOIL COVERINGS}

\begin{abstract}
The objective of this work was to evaluate request energetic demand by a seeder offered commercially for no-tillage, submitted to four displacement speeds and three soil covering conditions in soybean culture implantation. The experiment was installed at the Cazarotto Small Farm, located in Iguatemi District, municipal district of Maringá - PR, Brazil, in Haplotox Soil. It was used split-plot design. The main treatments were three soil-covering conditions (spontaneous vegetation, black oat desiccated and black oat desiccated + rolled) and the secondary ones, the four forward speeds $(4.7 ; 5.4$; 6.5 e $7.2 \mathrm{~km} \mathrm{~h}^{-1}$ ). The studied variables were draw bar pull, power requirement, and wheel drive slip and consumption fuel. The draw bar pull was influenced by the forward speed and for the soil covering conditions. The wheel drive slip was not influenced by the treatments. The hourly fuel consumption was larger in the spontaneous vegetation covering condition.
\end{abstract}

KEYWORDS: draw bar pull, power requirement, fuel consumption.

\footnotetext{
${ }^{1}$ Extraído da Dissertação de Mestrado do primeiro autor.

${ }^{2}$ Enga ${ }^{a}$ Agrícola, Departamento de Agronomia, Universidade Estadual de Maringá, UEM, Maringá - PR, Fone: (0XX44) 32614316, vcbortolotto@pop.com.br

${ }^{3}$ Eng ${ }^{\mathbf{0}}$ Agrícola, Prof. Doutor, Departamento de Agronomia, UEM, Maringá - PR.

${ }^{4}$ Técnico em Agropecuária, Formando do Curso de Agronomia, UEM, Maringá - PR.

Recebido pelo Conselho Editorial em: 16-12-2005

Aprovado pelo Conselho Editorial em: 15-3-2006 


\section{INTRODUÇÃO}

Segundo SILVA (2000), os maiores índices de mecanização agrícola estão concentrados nas operações de preparo do solo. Porém, o uso inadequado de práticas e equipamentos agrícolas são os principais fatores da degradação do solo, podendo, em algumas situações, resultar em condições limitantes ao desenvolvimento das culturas. Sistemas alternativos de manejo do solo com o mínimo de mobilização e que mantêm consideráveis quantidades de resíduos vegetais na superfície, vêm se destacando no Brasil.

Para CASÃO JÚNIOR et al. (2000), a consolidação do sistema de semeadura direta depende da necessidade de solucionar problemas por ocasião da sua instalação, como, por exemplo, os de compactação do solo, baixos teores de matéria orgânica, baixa fertilidade, presença de plantas daninhas e elevado consumo energético em função de seleção inadequada das máquinas existentes.

Um fator determinante no sucesso do sistema de semeadura direta é a escolha de espécies de cobertura de solo com características adequadas para a manutenção ou elevação da produtividade de grãos das culturas cultivadas em sucessão. Para beneficiar esse sistema, as espécies de cobertura devem proteger o solo e melhorar as suas características físicas e químicas e, para a cultura subseqüente, devem incrementar a produtividade de grãos e o suprimento de nitrogênio (AITA, 1997 citado por ARGENTA et al., 2001).

A utilização adequada de máquinas e equipamentos agrícolas melhora a eficiência operacional, aumenta a capacidade efetiva de trabalho, facilita as tarefas do homem no campo, possibilita a expansão das áreas de cultivo, proporciona melhores produtividades e permite atender ao cronograma de atividades em um tempo hábil (MODOLO, 2003). MANTOVANI et al. (1992) concluíram que a potência requerida para tracionar semeadoras-adubadoras era menor do que as recomendadas nos catálogos promocionais dos fabricantes. Segundo PEREIRA (1998), o gasto com combustível é um componente importante na composição dos custos de uma lavoura. BEUTLER et al. (2003a) concluíram que, na semeadura direta, o aumento da resistência à penetração e a maior cobertura por resíduos culturais resultam em maior patinagem do trator. $\mathrm{O}$ valor da patinagem influi no desgaste do pneu, consumo de combustível e na força de tração disponível na barra de tração (REIS et al., 1999).

BEUTLER et al. (2003b) avaliaram a demanda de tração exigida por uma haste sulcadora tipo facão, em função do tipo de cobertura residual do solo (campo nativo dessecado, aveia e aveia + ervilhaca), número de linhas de semeadura (cultura do milho e da soja, com três e cinco linhas, respectivamente) e da profundidade de atuação da mesma para deposição de adubo $(6 \mathrm{e} 12 \mathrm{~cm})$. Verificaram que os maiores valores de força de tração foram obtidos na semeadura direta sobre o campo nativo dessecado e os menores sobre culturas de cobertura de inverno. O número de linhas e a profundidade de semeadura afetaram os esforços requeridos na tração do sulcador de adubo tipo facão.

Em virtude do grande número de fatores que influenciam no desempenho energético de conjuntos motomecanizados como trator/semeadora e da complexidade de suas interações, há a necessidade de estudos específicos visando a identificar as demandas energéticas dos diversos componentes e dos mecanismos de ação. Este trabalho teve o objetivo de avaliar a demanda energética requerida por uma semeadora-adubadora em diferentes condições de coberturas do solo e velocidades de deslocamento, na operação de semeadura direta da soja.

\section{MATERIAL E MÉTODOS}

Os ensaios foram realizados no Sítio Cazarotto, localizado no Distrito de Iguatemi, município de Maringá, região noroeste do Estado do Paraná, tendo como localização geográfica o paralelo $23^{\circ} 21^{\text {' }}$ 12 " ao sul e o meridiano $52^{\circ} 04^{\prime} 21^{\prime \prime}$ a oeste, com altitude em torno de $530 \mathrm{~m}$. O clima da região, segundo Köeppen, é do tipo Cfa. O solo foi classificado como Latossolo Vermelho distrófico 
(EMBRAPA, 1999) com relevo suave-ondulado. A área utilizada estava sendo cultivada sob sistema de semeadura direta há oito anos, com rotação de culturas com soja e milho, no verão, e aveia, trigo ou pousio, no inverno.

O preparo da área experimental, visando à instalação dos ensaios, foi realizado durante o inverno, permanecendo pousio nas áreas destinadas aos tratamentos com vegetação espontânea, e implantação da cultura da aveia (19-6-2003) nas parcelas destinadas às demais condições de cobertura do solo. Em 22-10-2003, realizou-se a dessecação em área total (tanto parcelas com vegetação espontânea como as com aveia-preta), com herbicidas glyphosate e 2,4 D. As parcelas com aveiapreta, sorteadas com o tratamento onde a condição de cobertura do solo era aveia rolada, foram tombadas com rolo-faca, na mesma direção da semeadura da soja, em 3-11-2003 (dia anterior aos ensaios).

Foram estabelecidas combinações entre condições de cobertura do solo e velocidades de semeadura. Foi utilizado o delineamento de blocos ao acaso, em arranjo de parcelas subdivididas ("split-splot"), em que os tratamentos principais eram condições de cobertura do solo (vegetação espontânea, aveia dessecada e aveia dessecada + rolada) e os tratamentos secundários as velocidades de deslocamento $\left(4,7 ; 5,4 ; 6,5\right.$ e 7,2 $\left.\mathrm{km} \mathrm{h}^{-1}\right)$. Os tratamentos secundários (subparcelas) possuíam quatro repetições, cada subparcela media $5 \mathrm{~m}$ de largura por $40 \mathrm{~m}$ de comprimento, onde os primeiros $25 \mathrm{~m}$ eram o comprimento útil e o restante para manobras e nivelamento da célula de carga.

Utilizou-se de uma semeadora-adubadora de precisão marca Marchesan, modelo PST3-TRA, ano de fabricação 2001, equipada com nove linhas espaçadas a $0,45 \mathrm{~m}$ e dotada dos seguintes mecanismos: disco liso para corte de cobertura com 15" de diâmetro; sulcador de fertilizantes tipo haste sulcadora com tubo condutor; sulcador para sementes tipo discos duplos defasados com 13"x 15" de diâmetro; duas rodas compactadoras e reguladoras de profundidade de semeadura com banda de borracha flexível e duas rodas estreitas em "V" para cobertura das sementes. Foram utilizados na operação dois tratores: um da marca Valmet, modelo $880(63,2 \mathrm{~kW} / 86 \mathrm{cv})$ e outro da marca Massey Ferguson, modelo $292(77 \mathrm{~kW} / 105 \mathrm{cv})$ com TDA. O primeiro foi utilizado para tracionar a semeadora e o segundo para tracionar o conjunto trator/semeadora através de um cabo de aço para que a célula de carga utilizada na aquisição de dados de força de tração ficasse nivelada, sendo a cultura-teste a soja (Glycine max L.). Os reservatórios de sementes e de adubo foram abastecidos e mantidos em torno de $75 \%$ de sua capacidade.

Antes da semeadura, realizaram-se amostragens para a determinação do teor de água, densidade do solo, microporosidade, macroporosidade, porosidade total na profundidade de 0 a $15 \mathrm{~cm}$ e matéria seca sobre o solo. As variáveis estudadas foram: força de tração média, por linha de semeadura e máxima na barra de tração, patinagem do rodado traseiro do trator, consumo de combustível horário e em função da área trabalhada, potência média e máxima e demanda de energia em função da área trabalhada.

As velocidades de deslocamento foram obtidas em função do escalonamento de marchas e rotação do motor ( $3^{\text {a }} \mathrm{A}$ reduzida a $1.400 \mathrm{rpm}\left(4,7 \mathrm{~km} \mathrm{~h}^{-1}\right) ; 1^{-} \mathrm{B}$ simples a $1.400 \mathrm{rpm}\left(5,4 \mathrm{~km} \mathrm{~h}^{-1}\right) ; 3^{-}$A reduzida a $1.900 \mathrm{rpm}\left(6,5 \mathrm{~km} \mathrm{~h}^{-1}\right) ; 1^{\text {a }} \mathrm{B}$ simples a $\left.1.900 \mathrm{rpm}\left(7,2 \mathrm{~km} \mathrm{~h}^{-1}\right)\right)$ do trator de marca Massey Ferguson, utilizado na semeadura. Para determinar a velocidade instantânea de deslocamento, utilizouse de unidade de radar da "Dickey-John", modelo DjRVS II, com erro $\pm 3 \%$ para velocidades entre 3,2 e $70,8 \mathrm{~km} \mathrm{~h}^{-1}$.

Para a determinação da força de tração média e máxima na barra de tração, utilizou-se de célula de carga marca TRANSTEC, modelo N-400, com capacidade de carga nominal de 5 tf. A força de tração por linha de semeadura foi obtida dividindo-se a força média na barra de tração pelo número de linhas (9). 
A determinação da patinagem das rodas motrizes do trator foi realizada utilizando-se de geradores de impulsos da S\&E Instrumentos de Teste e Medições, modelo GIDP-60-12V. A patinagem dos rodados do trator foi obtida da relação entre o número de voltas registrado para cada rodado ao percorrer a parcela e o comprimento real da parcela experimental, de acordo com SILVA (2000).

O consumo horário de combustível foi determinado utilizando-se de medidores de fluxo da Oval, modelo LSN40, com sinal de saída do tipo impulso e precisão de $1 \mathrm{~mL}$ por impulso. O consumo de combustível, em função da área trabalhada, foi obtido dividindo-se o consumo horário pela capacidade de campo efetiva.

A potência média e máxima $(\mathrm{kW})$ resultou da multiplicação da força de tração (kgf) pela velocidade de deslocamento $\left(\mathrm{m} \mathrm{s}^{-1}\right)$, respectivas aos tratamentos, e pelo fator de conversão $(0,0098096)$. A demanda de energia, em função da área trabalhada, foi obtida dividindo-se a potência média pela capacidade de campo efetiva, respectivas aos tratamentos.

Para armazenar os dados da célula de carga e geradores de impulso, foi utilizado um sistema de aquisição de dados da marca CAMPBEL SCIENTIFIC, modelo CR23X.

Todos os parâmetros monitorados correspondem à média aritmética dos valores armazenados durante o deslocamento do conjunto trator/semeadora-adubadora em cada parcela experimental. Os dados foram submetidos à análise de variância e teste de Scott-Knott, a 5\% de significância, para a comparação das médias.

\section{RESULTADOS E DISCUSSÃO}

Embora houvesse diferentes condições de cobertura do solo, não foram encontradas diferenças estatísticas, a 5\% de probabilidade, para as variáveis teor de água, densidade do solo, microporosidade, macroporosidade, porosidade total e matéria seca, entre todas as subparcelas (tratamentos). Os valores variaram para o teor de água de 12,59 a 14,26\%; densidade do solo de 1,58 a 1,67 $\mathrm{g} \mathrm{cm}^{-3}$; microporosidade do solo de 28,55 a $31,03 \%$; macroporosidade de 4,63 a $7,55 \%$; porosidade total de 34,23 a $36,61 \%$ na profundidade de $0-15 \mathrm{~cm}$, e a matéria seca de $3.187,80$ a $3.869,80 \mathrm{~kg} \mathrm{ha}^{-1}$.

Os valores obtidos para força média de tração $(\mathrm{kN})$, exigida pela semeadora, são apresentados na Tabela 1. Os valores foram significativos a $5 \%$ de probabilidade para o fator velocidade, cobertura do solo e seu desdobramento. A condição de cobertura do solo com vegetação espontânea foi a que exigiu maior força de tração, seguida da aveia dessecada e, por último, a aveia rolada. Dentre as plantas que se encontravam na condição de cobertura do solo com vegetação espontânea, predominavam a trapoeraba (Commelina benghalensis), o carrapicho (Cenchruf echinapuf) e o capim-marmelada (Brachiaria plantaginea) em forma de touceiras, o que pode justificar a maior exigência de força de tração. LEVIEN (1999) estudou condições de cobertura do solo em diferentes métodos de preparo do solo e não encontrou diferença significativa para a variável força média de tração, em função das condições de cobertura do solo com aveia dessecada e aveia rolada.

$\mathrm{Na}$ Tabela 2, são apresentados os valores para a força de tração por linha de semeadura $(\mathrm{kN})$. Os valores seguiram a mesma tendência da força de tração média. Os valores para a força de tração por linha de semeadura se apresentaram dentro do intervalo de $3,4 \mathrm{kN} \pm 35 \%$, apresentado pela ASAE (1999).

Para a força de tração máxima, os valores foram significativos a 5\% de probabilidade para os fatores velocidade e cobertura do solo e seu desdobramento (Tabela 3). A condição de cobertura do solo com vegetação espontânea foi a que obteve maiores valores de força, sendo que as aveias dessecadas e roladas não diferiram. Para o fator velocidade, os maiores valores foram encontrados nas velocidades de 6,5 e 7,2 $\mathrm{km} \mathrm{h}^{-1}$ e as menores nas velocidades de 4,7 e 5,4 $\mathrm{km} \mathrm{h}^{-1}$. Segundo alguns 
autores, os valores máximos de força de tração podem ocorrer também devido a irregularidades e desuniformidades do terreno, diferenças de profundidade de semeadura ou embuchamentos momentâneos (LEVIEN, 1999) ou mesmo devido a diferenças de resistência do solo ao corte (MODOLO, 2003). A força de tração máxima foi 16 a 20\% maior que a força média requerida.

TABELA 1. Valores médios obtidos para a força de tração média requerida na barra de tração (kN).

\begin{tabular}{|c|c|c|c|c|}
\hline \multirow{3}{*}{ Velocidade $\left(\mathrm{km} \mathrm{h}^{-1}\right)$} & \multicolumn{3}{|c|}{ Força de Tração Média Requerida (kN) } & \multirow{3}{*}{$\begin{array}{c}\text { Médias } \\
\text { (Velocidade) }\end{array}$} \\
\hline & \multicolumn{3}{|c|}{ Coberturas } & \\
\hline & Vegetação Espontânea & Aveia Dessecada & Aveia Rolada & \\
\hline 4,7 & $22,34 \mathrm{Ab}$ & $21,10 \mathrm{Ba}$ & $20,64 \mathrm{Ba}$ & $21,36 \mathrm{~b}$ \\
\hline 5,4 & $22,62 \mathrm{Ab}$ & $21,62 \mathrm{Ba}$ & $20,36 \mathrm{Ca}$ & $21,53 \mathrm{~b}$ \\
\hline 6,5 & $23,27 \mathrm{Aa}$ & $21,49 \mathrm{Ba}$ & $20,90 \mathrm{Ba}$ & $21,76 \mathrm{a}$ \\
\hline 7,2 & $22,53 \mathrm{Ab}$ & $21,69 \mathrm{Ba}$ & $21,07 \mathrm{Ba}$ & $21,89 \mathrm{a}$ \\
\hline Médias (Cob.) & $22,69 \mathrm{~A}$ & $21,47 \mathrm{~B}$ & $20,74 \mathrm{C}$ & \\
\hline
\end{tabular}

Médias seguidas de letras maiúsculas diferentes na linha e minúsculas na coluna diferem entre si, pelo Teste de ScottKnott, a $5 \%$ de probabilidade.

TABELA 2. Valores médios obtidos para a força de tração por linha de semeadura $\left(\mathrm{kN} \mathrm{linha}^{-1}\right)$.

\begin{tabular}{|c|c|c|c|c|}
\hline \multirow{3}{*}{ Velocidade $\left(\mathrm{km} \mathrm{h}^{-1}\right)$} & \multicolumn{3}{|c|}{ Força de Tração por Linha de Semeadura $\left(\mathrm{kN}\right.$ linha $\left.^{-1}\right)$} & \multirow{3}{*}{$\begin{array}{c}\text { Médias } \\
\text { (Velocidade) }\end{array}$} \\
\hline & \multicolumn{3}{|c|}{ Coberturas } & \\
\hline & Vegetação Espontânea & Aveia Dessecada & Aveia Rolada & \\
\hline 4,7 & $24,82 \mathrm{Ab}$ & $23,44 \mathrm{Ba}$ & $22,94 \mathrm{Ba}$ & $2.373,04 \mathrm{~b}$ \\
\hline 5,4 & $25,13 \mathrm{Ab}$ & $24,02 \mathrm{Ba}$ & $22,62 \mathrm{Ca}$ & $2.392,42 b$ \\
\hline 6,5 & $25,86 \mathrm{Aa}$ & $23,88 \mathrm{Ba}$ & $23,22 \mathrm{Ba}$ & $2.431,70 \mathrm{a}$ \\
\hline 7,2 & $25,04 \mathrm{Ab}$ & $24,10 \mathrm{Ba}$ & $23,41 \mathrm{Ba}$ & $2.418,04 \mathrm{a}$ \\
\hline Médias (Cob.) & $25,21 \mathrm{~A}$ & $23,86 \mathrm{~B}$ & $23,05 \mathrm{~B}$ & \\
\hline
\end{tabular}

Médias seguidas de letras maiúsculas diferentes na linha e minúsculas na coluna diferem entre si, pelo Teste de ScottKnott, a $5 \%$ de probabilidade.

TABELA 3. Valores médios obtidos para a força de tração máxima requerida $(\mathrm{kN})$.

\begin{tabular}{|c|c|c|c|c|}
\hline \multirow{3}{*}{ Velocidade $\left(\mathrm{km} \mathrm{h}^{-1}\right)$} & \multicolumn{3}{|c|}{ Força de Tração Máxima Requerida $(\mathrm{kN})$} & \multirow{3}{*}{$\begin{array}{c}\text { Médias } \\
\text { (Velocidade) }\end{array}$} \\
\hline & \multicolumn{3}{|c|}{ Coberturas } & \\
\hline & Vegetação Espontânea & Aveia Dessecada & Aveia Rolada & \\
\hline 4,7 & $26,97 \mathrm{Aa}$ & $24,27 \mathrm{Ba}$ & $25,43 \mathrm{Ba}$ & $25,55 \mathrm{~b}$ \\
\hline 5,4 & $27,61 \mathrm{Aa}$ & $25,27 \mathrm{Ba}$ & $25,17 \mathrm{Ba}$ & $26,02 \mathrm{~b}$ \\
\hline 6,5 & $28,34 \mathrm{Aa}$ & $25,44 \mathrm{Ba}$ & $26,12 \mathrm{Ba}$ & $26,63 \mathrm{a}$ \\
\hline 7,2 & $27,72 \mathrm{Aa}$ & $26,77 \mathrm{Aa}$ & $26,84 \mathrm{Aa}$ & $27,11 \mathrm{a}$ \\
\hline Médias (Cob.) & $27,66 \mathrm{~A}$ & $25,43 \mathrm{~B}$ & $25,89 \mathrm{~B}$ & \\
\hline
\end{tabular}

Médias seguidas de letras maiúsculas diferentes na linha e minúsculas na coluna diferem entre si, pelo Teste de ScottKnott, a $5 \%$ de probabilidade.

Os valores para a patinagem do rodado traseiro do trator são apresentados na Tabela 4. Não houve diferenças significativas. Os valores da patinagem apresentaram-se dentro e um pouco acima do intervalo de 7 a 10\% recomendados pela ASAE (1989) para obtenção da máxima eficiência de operação em solos não-mobilizados. Cabe ressaltar que o trator possuía TDA, e a mesma estava acionada.

Os valores médios obtidos para o consumo horário de combustível são apresentados na Tabela 5. Os fatores cobertura, velocidade e seu desdobramento foram significativos. $\mathrm{O}$ maior consumo de 
combustível foi verificado na condição de cobertura do solo com vegetação espontânea e corresponde ao tratamento que também requereu a maior força de tração, tanto média (Tabela 1) como máxima (Tabela 3), sendo que, em média, todas as velocidades diferiram entre si. As exceções foram as condições de cobertura com vegetação espontânea e aveia dessecada.

TABELA 4. Valores médios obtidos para a patinagem do rodado traseiro do trator.

\begin{tabular}{|c|c|c|c|c|}
\hline \multirow{3}{*}{ Velocidade $\left(\mathrm{km} \mathrm{h}^{-1}\right)$} & \multicolumn{3}{|c|}{ Patinagem do Rodado Traseiro do Trator (\%) } & \multirow{3}{*}{$\begin{array}{c}\text { Médias } \\
\text { (Velocidade) }\end{array}$} \\
\hline & \multicolumn{3}{|c|}{ Coberturas } & \\
\hline & Vegetação Espontânea & Aveia Dessecada & Aveia Rolada & \\
\hline 4,7 & 8,34 & 10,36 & 12,97 & 10,56 \\
\hline 5,4 & 10,36 & 12,38 & 9,61 & 10,78 \\
\hline 6,5 & 9,35 & 12,63 & 11,96 & 11,31 \\
\hline 7,2 & 9,86 & 12,04 & 11,03 & 10,98 \\
\hline Médias (Cob.) & 9,48 & 11,85 & 11,39 & \\
\hline
\end{tabular}

Médias seguidas de letras maiúsculas diferentes na linha e minúsculas na coluna diferem entre si, pelo Teste de ScottKnott, a $5 \%$ de probabilidade.

TABELA 5. Valores médios obtidos para o consumo horário de combustível.

\begin{tabular}{|c|c|c|c|c|}
\hline \multirow{3}{*}{ Velocidade $\left(\mathrm{km} \mathrm{h}^{-1}\right)$} & \multicolumn{3}{|c|}{ Consumo de Combustível $\left(\mathrm{L} \mathrm{h}^{-1}\right)$} & \multirow{3}{*}{$\begin{array}{c}\text { Médias } \\
\text { (Velocidade) }\end{array}$} \\
\hline & \multicolumn{3}{|c|}{ Coberturas } & \\
\hline & Vegetação Espontânea & Aveia Dessecada & Aveia Rolada & \\
\hline 4,74 & $11,64 \mathrm{~b}$ & $11,09 \mathrm{c}$ & $10,91 \mathrm{~d}$ & $11,21 \mathrm{~d}$ \\
\hline 5,41 & $12,54 \mathrm{~b}$ & $13,01 \mathrm{~b}$ & $12,10 \mathrm{c}$ & $12,55 \mathrm{c}$ \\
\hline 6,47 & $17,04 \mathrm{a}$ & $16,40 \mathrm{a}$ & $16,20 \mathrm{~b}$ & $16,55 \mathrm{~b}$ \\
\hline 7,24 & $17,61 \mathrm{a}$ & $16,88 \mathrm{a}$ & $17,56 \mathrm{a}$ & $17,35 \mathrm{a}$ \\
\hline Médias (Cob.) & $14,71 \mathrm{~A}$ & $14,34 \mathrm{~B}$ & $14,19 \mathrm{~B}$ & \\
\hline
\end{tabular}

Médias seguidas de letras maiúsculas diferentes na linha e minúsculas na coluna diferem entre si, pelo Teste de ScottKnott, a 5\% de probabilidade.

Os valores médios obtidos para o consumo de combustível, em função da área trabalhada, são apresentados na Tabela 6. O fator velocidade foi significativo, e o fator cobertura foi significativo apenas para a velocidade de $5,4 \mathrm{~km} \mathrm{~h}^{-1}$. Os maiores valores encontram-se na velocidade de $6,5 \mathrm{~km} \mathrm{~h}^{-1} \mathrm{e}$ os demais não diferem entre si.

TABELA 6. Valores médios para o consumo de combustível em função da área trabalhada.

\begin{tabular}{|c|c|c|c|c|}
\hline \multirow{3}{*}{ Velocidade $\left(\mathrm{km} \mathrm{h}^{-1}\right)$} & \multicolumn{3}{|c|}{ Consumo de Combustível em Função da Área Trabalhada $\left(\mathrm{L} \mathrm{ha}^{-1}\right)$} & \multirow{3}{*}{$\begin{array}{c}\text { Médias } \\
\text { (Velocidade) }\end{array}$} \\
\hline & \multicolumn{3}{|c|}{ Coberturas } & \\
\hline & Vegetação Espontânea & Aveia Dessecada & Aveia Rolada & \\
\hline 4,7 & $6,12 \mathrm{Ab}$ & $5,68 \mathrm{Ab}$ & $5,83 \mathrm{Aa}$ & $5,88 \mathrm{~b}$ \\
\hline 5,4 & $5,68 \mathrm{Bb}$ & $6,10 \mathrm{Aa}$ & $5,58 \mathrm{Ba}$ & $5,79 \mathrm{~b}$ \\
\hline 6,5 & $6,50 \mathrm{Aa}$ & $6,40 \mathrm{Aa}$ & $6,22 \mathrm{Aa}$ & $6,37 \mathrm{a}$ \\
\hline 7,2 & $6,05 \mathrm{Ab}$ & $5,95 \mathrm{Ab}$ & 5,93 Aa & $5,98 \mathrm{~b}$ \\
\hline Médias (Cob.) & 6,09 & 6,03 & 5,89 & \\
\hline
\end{tabular}

Médias seguidas de letras maiúsculas diferentes na linha e minúsculas na coluna diferem entre si, pelo Teste de ScottKnott, a $5 \%$ de probabilidade.

Para a demanda de potência média requerida, os fatores: cobertura do solo, velocidades de deslocamento e seu desdobramento foram significativos, a 5\% de probabilidade (Tabela 7). Observa-se 
que a condição de cobertura com vegetação espontânea foi a que obteve maior requerimento de potência, enquanto a aveia dessecada e a rolada não diferiram entre si. Isso pode ser explicado, como já mencionado, pela presença de touceiras de capim-marmelada entre as culturas que predominavam na condição de cobertura com vegetação espontânea. As velocidades mais altas obtiveram maior demanda de potência.

TABELA 7. Valores médios obtidos para a potência média requerida.

\begin{tabular}{|c|c|c|c|c|}
\hline \multirow{3}{*}{ Velocidade $\left(\mathrm{km} \mathrm{h}^{-1}\right)$} & \multicolumn{3}{|c|}{ Potência Média Requerida $(\mathrm{kW})$} & \multirow{3}{*}{$\begin{array}{c}\text { Médias } \\
\text { (Velocidade) }\end{array}$} \\
\hline & \multicolumn{3}{|c|}{ Coberturas } & \\
\hline & Vegetação Espontânea & Aveia Dessecada & Aveia Rolada & \\
\hline 4,7 & $28,70 \mathrm{Ad}$ & $28,42 \mathrm{Ad}$ & $26,49 \mathrm{Ad}$ & $27,87 \mathrm{~d}$ \\
\hline 5,4 & $34,26 \mathrm{Ac}$ & $31,87 \mathrm{Bc}$ & $29,95 \mathrm{Bc}$ & $32,03 \mathrm{c}$ \\
\hline 6,5 & $41,55 \mathrm{Ab}$ & $37,97 \mathrm{Bb}$ & $37,25 \mathrm{Bb}$ & $38,92 \mathrm{~b}$ \\
\hline 7,2 & 45,08 Aa & $42,13 \mathrm{Ba}$ & $42,54 \mathrm{Ba}$ & $43,25 \mathrm{a}$ \\
\hline Médias (Cob.) & $37,40 \mathrm{~A}$ & $35,10 \mathrm{~B}$ & $34,06 \mathrm{~B}$ & \\
\hline
\end{tabular}

Médias seguidas de letras maiúsculas diferentes na linha e minúsculas na coluna diferem entre si, pelo Teste de ScottKnott, a $5 \%$ de probabilidade.

A demanda da potência máxima $(\mathrm{kW})$ na barra de tração, exigida pela semeadora, é apresentada na Tabela 8. O fator velocidade de deslocamento foi significativo, a 5\% de probabilidade. Observa-se que a condição de cobertura com vegetação espontânea foi a que obteve o maior requerimento de potência, enquanto a aveia dessecada e a rolada não diferiram entre si, seguindo a tendência da potência média (Tabela 7). Os maiores valores de potência máxima foram encontrados na condição de cobertura com vegetação espontânea. Nessas parcelas, foi observado, visualmente, menor uniformidade da vegetação, havendo em certos pontos maior concentração de touceiras de capimmarmelada, as quais devem ter exigido maior potência do trator.

TABELA 8. Valores médios obtidos para a potência máxima requerida.

\begin{tabular}{|c|c|c|c|c|}
\hline \multirow{3}{*}{ Velocidade $\left(\mathrm{km} \mathrm{h}^{-1}\right)$} & \multicolumn{3}{|c|}{ Potência Máxima Requerida (kW) } & \multirow{3}{*}{$\begin{array}{c}\text { Médias } \\
\text { (Velocidade) }\end{array}$} \\
\hline & \multicolumn{3}{|c|}{ Coberturas } & \\
\hline & Vegetação Espontânea & Aveia Dessecada & Aveia Rolada & \\
\hline 4,7 & $34,65 \mathrm{Ad}$ & $32,73 \mathrm{Ad}$ & $32,61 \mathrm{Ad}$ & $33,33 \mathrm{~d}$ \\
\hline 5,4 & $41,82 \mathrm{Ac}$ & $37,28 \mathrm{Bc}$ & $37,05 \mathrm{Bc}$ & $38,72 \mathrm{c}$ \\
\hline 6,5 & $50,60 \mathrm{Ab}$ & 44,94 Bb & $46,54 \mathrm{Bb}$ & $47,36 \mathrm{~b}$ \\
\hline 7,2 & $55,50 \mathrm{Aa}$ & $51,99 \mathrm{Aa}$ & $54,20 \mathrm{Aa}$ & $53,90 \mathrm{a}$ \\
\hline Médias (Cob.) & $45,64 \mathrm{~A}$ & $41,73 \mathrm{~B}$ & $42,60 \mathrm{~B}$ & \\
\hline
\end{tabular}

Médias seguidas de letras maiúsculas diferentes na linha e minúsculas na coluna diferem entre si, pelo Teste de ScottKnott, a 5\% de probabilidade.

Os valores calculados de demanda de energia, em função da área trabalhada (Tabela 9), refletem a combinação dos resultados de potência e área trabalhada por unidade de tempo. A condição com vegetação espontânea obteve maior uso de energia que as demais coberturas, enquanto a aveia rolada o menor. Para o desdobramento, as aveias dessecadas e roladas não diferiram entre si, com exceção da velocidade: $5,4 \mathrm{~km} \mathrm{~h}^{-1}$. 
TABELA 9. Valores médios para a demanda de energia em função da área trabalhada.

\begin{tabular}{|c|c|c|c|c|}
\hline \multirow{3}{*}{ Velocidade $\left(\mathrm{km} \mathrm{h}^{-1}\right)$} & \multicolumn{3}{|c|}{ Demanda de Energia em Função da Área Trabalhada $\left(\mathrm{kW}\right.$ ha $\left.\mathrm{h}^{-1}\right)$} & \multirow{3}{*}{$\begin{array}{c}\text { Médias } \\
\text { (Velocidade) }\end{array}$} \\
\hline & \multicolumn{3}{|c|}{ Coberturas } & \\
\hline & Vegetação Espontânea & Aveia Dessecada & Aveia Rolada & \\
\hline 4,7 & $15,09 \mathrm{~A}$ & $14,53 \mathrm{~B}$ & $14,16 \mathrm{~B}$ & 14,59 \\
\hline 5,4 & $15,48 \mathrm{~A}$ & $14,90 \mathrm{~A}$ & $13,82 \mathrm{~B}$ & 14,73 \\
\hline 6,5 & $15,84 \mathrm{~A}$ & $14,82 \mathrm{~B}$ & $14,31 \mathrm{~B}$ & 14,90 \\
\hline 7,2 & $15,48 \mathrm{~A}$ & $14,85 \mathrm{~B}$ & $14,36 \mathrm{~B}$ & 14,99 \\
\hline Médias (Cob.) & $15,47 \mathrm{~A}$ & $14,77 \mathrm{~B}$ & $14,16 \mathrm{C}$ & \\
\hline
\end{tabular}

Médias seguidas de letras maiúsculas diferentes na linha e minúsculas na coluna diferem entre si, pelo Teste de ScottKnott, a $5 \%$ de probabilidade.

\section{CONCLUSÕES}

A força de tração foi influenciada pela velocidade de deslocamento e pelas condições de cobertura. A velocidade de 7,2 $\mathrm{km} \mathrm{h}^{-1}$ e a condição de cobertura com vegetação espontânea exigiram maiores valores de força de tração. A patinagem do rodado traseiro do trator não foi influenciada pelos tratamentos. O consumo horário de combustível foi maior na condição de cobertura com vegetação espontânea.

\section{REFERÊNCIAS}

ARGENTA, G.; SILVA, P.R.F. da; FLECK, N.G.; BORTOLINI, C.G.; NEVES, R.; AGOSTINETTO, D. Efeitos do manejo mecânico e químico da aveia-preta no milho em sucessão e no controle do capim-papuã. Pesquisa Agropecuária. Brasileira, Brasília, v.36, n.6, p.851-60, 2001.

ASAE. Agricultural machinery management. In: ASAE standards 1999: standards engineering pratices data. St. Joseph, 1999. p.359-66.

ASAE Standards S209.5. Agricultural tractor test code. In: ASAE standards 1989: standards engineering pratices data. St. Joseph, 1989. p.44-8.

BEUTLER, J.F.; LEVIEN, R.; TREIN, C.R. Força de tração em haste sulcadora tipo facão, operando em diferentes resíduos culturais e configurações da semeadora. In: CONGRESSO BRASILEIRO DE ENGENHARIA AGRÍCOLA, 32., 2003, Goiânia. Anais... Goiânia: Associação Brasileira de Engenharia Agrícola, 2003a. 1 CD-ROM.

BEUTLER, J.F.; LEVIEN, R.; TREIN, C.R.; HERZOG, R.L.S. Patinagem em diferentes sistemas de preparo do solo. In.: CONGRESSO ARGENTINO DE INGENIERIA AGRÍCOLA, 7., 2003, Balcarce. Resumenes...Balcarce: INTA/UNdMP, 2003b. 1 CD-ROM.

CASÃO JUNIOR, R.; ARAÚJO, A.G. de; RALISCH, R. Desempenho da semeadora-adubadora Magnun 2850 em plantio direto no basalto paranaense. Pesquisa Agropecuária. Brasileira, Brasília, v.35, n.3, p.523-32, 2000.

EMPRESA BRASILEIRA DE PESQUISA AGROPECUÁRIA - EMBRAPA. Sistema brasileiro de classificação de solos. 4 ${ }^{\mathrm{a}}$ Aproximação. Rio de Janeiro: Embrapa/CNPS, 1999. 169 p.

LEVIEN, R. Condições de cobertura e métodos de preparo do solo para a implantação da cultura do milho (Zea mays L.) 1999. 305 f. Tese (Doutorado em Energia na Agricultura)- Faculdade de Ciências Agronômicas, Universidade Estadual Paulista "Júlio de Mesquita Filho", Botucatu, 1999. 
MANTOVANI, E.C.; BERTAUX, S.; ROCHA, F.E.C. Avaliação da eficiência operacional de diferentes semeadoras-adubadoras de milho. Pesquisa Agropecuária Brasileira, Brasília, v.27, n.12, p.1579-86, 1992.

MODOLO, A.J. Demanda energética de uma semeadora-adubadora com diferentes unidades de semeadura. 2003. 78 f. Dissertação (Mestrado em Sistemas Agroindustriais) - Universidade Estadual do Oeste do Paraná, Cascavel, 2003.

PEREIRA, J.P.G. Balanço energético na implantação da cultura do milho. In: CONGRESO ARGENTINO DE INGENIERÍA RURAL, 5., 1998, La Plata. Trabalhos publicados... La Plata: Universidad Nacional La Plata, 1998. 1 CD-ROM.

REIS, A.V.; MACHADO, A.L.T.; TILLMANN, C.A.C.; MORAES, M.C.B. Motores, tratores, combustiveis e lubrificantes. Pelotas: UFPel, 1999. 315 p.

SILVA, S.L. Avaliação de semeadoras para plantio direto: demanda energética, distribuição longitudinal e profundidade de deposição de sementes em diferentes velocidades de deslocamento. 2000. 123 f. Tese (Doutorado em Energia na Agricultura) - Faculdade de Ciências Agronômicas, Universidade Estadual Paulista, Botucatu, 2000. 